\section{BMJ Open Respiratory Research}

\title{
Veterans Specific Activity Questionnaire (VSAQ): a new and efficient method of assessing exercise capacity in patients with pulmonary arteriovenous malformations
}

\author{
Filip Gawecki, ${ }^{1,2}$ Jonathan Myers, ${ }^{3}$ Claire L. Shovlin ${ }^{4,5}$
}

To cite: Gawecki F, Myers J, Shovlin CL. Veterans Specific Activity Questionnaire (VSAQ): a new and efficient method of assessing exercise capacity in patients with pulmonary arteriovenous malformations. BMJ Open Resp Res 2019;6:e000351. doi:10.1136/ bmjresp-2018-000351

- Additional material is published online only. To view please visit the journal online (http://dx.doi.org/10.1136/ bmjresp-2018-000351)

Received 29 August 2018 Accepted 20 November 2018

Check for updates

(C) Author(s) (or their employer(s)) 2019. Re-use permitted under CC BY-NC. No commercial re-use. See rights and permissions. Published by BMJ.

${ }^{1}$ Imperial College School of Medicine, London, UK ${ }^{2} \mathrm{NHLI}$ Respiratory Sciences, Imperial College London, London, UK

${ }^{3}$ Department of Cardiology, VA Palo Alto Health Care System, Palo Alto, California, USA ${ }^{4} \mathrm{NHLI}$ Vascular Sciences, Imperial College London, London, UK

${ }^{5}$ Respiratory Medicine, Imperial College Healthcare NHS Trust, London, UK

Correspondence to Professor Claire L. Shovlin; c.shovlin@imperial.ac.uk

\section{ABSTRACT}

Introduction Assessment of performance status is an important component of clinical management of patients with pulmonary arteriovenous malformations (PAVMs). Usual methods are time-consuming and insensitive to variations within normal or supranormal exercise capacity. Methods The Veterans Specific Activity Questionnaire (VSAQ) was modified to facilitate completion by patients independently. Patient-reported activity limitations were converted to the Medical Research Council (MRC) Dyspnoea Scale, New York Heart Association (NYHA) classification and metabolic equivalents (METs) in which 1 MET equals the consumption of $3.5 \mathrm{~mL} \mathrm{O}_{2}$ per kilogram of body weight per minute.

Results The study population consisted of 71 patients with PAVMs aged 20-85 (median 52) years. Oxygen saturation $\left(\mathrm{SaO}_{2}\right.$ ) was 80\%-99.5\% (median 96\%), and haemoglobin was 73-169 $\mathrm{g} / \mathrm{L}$ in women and 123-197 g/L in men $(p<0.0001)$. Arterial oxygen content $\left(\mathrm{CaO}_{2}\right)(1.34$ $\times$ [haemoglobin $\left.\times \mathrm{SaO}_{2}\right] / 100$ ) was maintained unless iron deficiency was present. Most patients (49/71,69\%) did not need to stop until activities more energetic than walking briskly at $4 \mathrm{mph}$ were achieved $(6.4 \mathrm{~km}$ per hour, VSAQ $>5$, MRC Dyspnoea Scale 1 or 2, NYHA class I). $\mathrm{SaO}_{2}$ was inversely associated with the MRC Dyspnoea Scale and NYHA class, but not the VSAQ. Raw VSAQ scores captured a marked difference between men and women. METs were also higher in men at 3.97-15.55 (median 8.84) kcal $/ \mathrm{kg} / \mathrm{min}$, compared with 1.33-14.4 (median 8.25) $\mathrm{kcal} / \mathrm{kg} / \mathrm{min}(\mathrm{p}=0.0039)$. There was only a modest association between METs and $\mathrm{SaO}_{2}(p=0.044)$, but a stronger association between METs and haemoglobin $(p=0.001)$. In crude and sex-adjusted regression, the $\mathrm{CaO}_{2}$ was more strongly associated with METs than either $\mathrm{SaO}_{2}$ or haemoglobin in isolation.

Conclusion The VSAQ, capturing patient-reported outcome measures, is an efficient and quantifiable measure of exercise capacity that can be readily employed in clinical services particularly where patients have normal to high exercise tolerance. In the PAVM population, exercise capacity reflects haemoglobin and $\mathrm{CaO}_{2}$ more than $\mathrm{SaO}_{2}$, even where $\mathrm{SaO}_{2}$ measurements are low.

\section{Key messages}

For patients with pulmonary arteriovenous malformations and normal to high exercise tolerance, conventional dyspnea scales do not capture reported variability.

- The Veterans Specific Activity Questionnaire (VSAQ) is an efficient and quantifiable measure of exercise capacity that discriminates between different levels of normal and athletic activity, in addition to mild, moderate and severe limitations.

- The VSAQ and its derived metabolic equivalents demonstrate that in the pulmonary arteriovenous malformation population, exercise capacity reflects haemoglobin and calculated arterial oxygen content more than oxygen saturation $\left(\mathrm{SaO}_{2}\right)$, even where $\mathrm{SaO}_{2}$ measurements are low.

\section{INTRODUCTION}

Pulmonary arteriovenous malformations (PAVMs) are rare abnormal communications between pulmonary arteries and pulmonary veins, resulting in an anatomical right-to-left shunt. ${ }^{1-4}$ The anatomical structures that are visible on thoracic imaging (CT being the most sensitive modality) distinguish PAVMs from more common forms of right-to-left shunts in healthy humans, for example through intrapulmonary arteriovenous anastomoses or intracardiac shunts. ${ }^{5}$

Patients with PAVMs are commonly hypoxaemic, ${ }^{346}$ but the majority have well-preserved exercise tolerance, even when oxygen saturation $\left(\mathrm{SaO}_{2}\right)$ of haemoglobin is $<92 \% .{ }^{6} 7$ This was formally demonstrated by cardiopulmonary exercise testing (CPET): In 21 patients with PAVMs, Borg Scale dyspnoea, maximal work rates and peak oxygen consumption $\left({ }^{\prime} \mathrm{O}_{2}\right)$ did not differ between patients categorised by severity of hypoxaemia, or before and 
after treatment that increased median $\mathrm{SaO}_{2}$ from $90 \%$ to $96 \% .^{8}$

Within the cohort of patients with PAVM, however, there are individuals with lower performance status and this influences subsequent management. ${ }^{9}$ Assessment of current exercise tolerance is therefore an important component of clinical review. Formal CPET assessments are informative, but can be time-consuming in routine clinical practice. ${ }^{6810}$ Formalised dyspnoea scales such as the Medical Research Council (MRC) ${ }^{11}$ or New York Heart Association $(\mathrm{NYHA})^{12}$ are problematic because the majority of patients with PAVMs are in class 1/I (normal) ${ }^{67}$ and patients report improvements or deteriorations which do not modify their status on these scales.

We therefore sought clinician-friendly, objective methods suitable for the broad exercise ranges of patients with PAVMs. In early project evaluations of available assessment tools, it became apparent that the most promising discriminatory tool appeared to be the Veterans Specific Activity Questionnaire $\left(\mathrm{VSAQ}^{13}\right)$, since this provided an initial 13-point scale, in contrast to the usual dyspnoea scales with $4-5$ points. ${ }^{1112}$ The VSAQ scale points discriminate between different levels of normal and athletic activity, in addition to limitations captured by conventional dyspnoea scales. Activities are listed in increasing difficulty and the user indicates activities that cause them to stop when performed for a period of time, whether that is due to breathlessness, chest discomfort, muscle pain or any other reasons (online supplementary figure 1). The limiting activity allows calculation of metabolic equivalents (METs), a measure of the amount of oxygen consumed while sitting down at rest. ${ }^{13}$ One MET is equal to the consumption of $3.5 \mathrm{~mL} \mathrm{O}_{2}$ per kilogram of body weight per minute. In the general population, numerous studies have validated the use of the VSAQ in the evaluation of exercise capacity, and have shown good correlation with CPET indices ${ }^{14-16}$ and mortality. ${ }^{17}$

We asked the question: Would the VSAQ provide a more sensitive and efficient way to capture performance status in patients with PAVMs than by CPET or use of conventional dyspnoea scales?

\section{METHODS}

\section{Study cohort}

The study subjects were a cohort of patients reviewed at a single UK institution for PAVMs and related conditions. Data were captured prospectively, and for the purposes of the current study case notes were retrospectively evaluated.

All reported evaluations were performed as part of routine clinical care as reported previously. ${ }^{6} 718 \mathrm{SaO}_{2}$ was measured by pulse oximetry (Ohmeda Biox 3900, Boulder, Colorado) while breathing room air, for $10 \mathrm{~min}$ in the erect posture, and the mean $\mathrm{SaO}_{2}$ was calculated across minutes $7-10 . \mathrm{SaO}_{2}{ }^{11819}$ and $\mathrm{PaO}_{2}^{2-4}$ are inversely related to the severity of right-to-left shunting through PAVMs, with the erect $\mathrm{SaO}_{2}$ better reflecting right-to-left shunt size than $\mathrm{SaO}_{2}$ in other postures, ${ }^{6}$ and more relevant for patients' daily activities. Patients were sent for same-day blood tests, which included full blood counts for haemoglobin and red cell indices. All patients with suspected PAVMs had the diagnosis confirmed or excluded by a dedicated thoracic CT scan, which for new patients was performed after completion of the VSAQ pulmonary function tests and initial clinical review.

\section{Development of assessment tools}

For patients presenting between 2006 and 2010, self-reported exercise capacity was assigned in a blinded manner to the MRC Dyspnoea Scale, ${ }^{11}$ to which a sixth category was added to categorise athletic individuals. ${ }^{67}$ In March 2017 the VSAQ was incorporated into routine clinic assessments and completed by the patient prior to clinician review. To compare the methods, VSAQ scores were converted to equivalent MRC Dyspnoea Scale and also to the NYHA heart failure classification. ${ }^{12}$

\section{Data analysis}

As in the original protocol ${ }^{13}$ and subsequent validations, ${ }^{14-17}$ the following formula was used to provide a score of predicted METs or exercise capacity based on the VSAQ score and the participant's age:

Predicted METs $=4.74+(0.97 \times$ VSAQ score $)-(0.06 \times$ Age $)$

The VSAQ and derived MRC, NYHA and METs data were assessed in relationship to patient-specific variables such as age, sex, $\mathrm{SaO}_{2}$, haemoglobin, and arterial oxygen content $\left(\mathrm{CaO}_{2}\right)$ which was calculated in millilitres of oxygen per litre of blood by the following formula:

$$
\mathrm{CaO}_{2}=\frac{1.34}{100} \times\left(\text { haemoglobin } \times \mathrm{SaO}_{2}\right)
$$

where haemoglobin was measured in $\mathrm{g} / \mathrm{L}, \mathrm{SaO}_{2}$ was expressed as a per cent and $1.34 \mathrm{~mL}$ is the empirically determined amount of oxygen carried per gram of haemoglobin. ${ }^{20}$

Incidental iron deficiency limits secondary erythrocytotic compensatory responses ${ }^{6}$ : as in ref 6 iron deficiency was assigned as absent (' 0 ') if ferritin, iron and transferrin saturation index (T/SI) were all clearly in the normal range (ferritin $>20 \mathrm{mg} / \mathrm{L}$, serum iron $>11 \mathrm{mmol} / \mathrm{L}$ and TSI $>20 \%$ ); present (' 1 ') if same-day ferritin was $<15 \mathrm{mg} / \mathrm{L}$, and also assigned as present (' 1 ') for individuals with both iron and TSSI clearly subnormal $(<7 \mathrm{mmol} / \mathrm{L}$ and $<20 \%$, respectively). All other combinations were assigned as intermediate/unknown ('.'). ${ }^{6}$

STATA IC V.15 was used to calculate the distribution of participant-specific variables to perform comparisons between groups and to generate graphs. Two group comparisons were by Mann-Whitney and three group by Kruskal-Wallis. Univariate and multivariate linear regression analyses were performed using normal quantile plots to select the most normally distributed outcome variable. 


\begin{tabular}{|c|c|c|}
\hline \multirow{3}{*}{$\begin{array}{l}\text { It is important for us } \\
\text { to understand } \\
\text { whether you have } \\
\text { normal, limited or } \\
\text { even high levels of } \\
\text { activity. }\end{array}$} & 1 & Eating, getting dressed or working at a desk \\
\hline & 2 & Taking a shower, shopping, cooking, walking down eight steps \\
\hline & 3 & $\begin{array}{l}\text { Walking slowly on a flat surface for } 100-200 \text { meters } \\
\text { A moderate amount of work around the house such as vacuuming, sweeping the } \\
\text { floors or carrying groceries }\end{array}$ \\
\hline \multirow{10}{*}{$\begin{array}{l}\text { On this list, please } \\
\text { circle any activity } \\
\text { that when performed } \\
\text { for a period of time, } \\
\text { would typically } \\
\text { make you to want to } \\
\text { stop. }\end{array}$} & 4 & $\begin{array}{l}\text { Light gardening work } \\
\text { Painting or light carpentry }\end{array}$ \\
\hline & 5 & $\begin{array}{l}\text { Walking briskly e.g. four miles per hour } \\
\text { Social dancing, washing the car }\end{array}$ \\
\hline & 6 & $\begin{array}{l}\text { Playing nine holes of golf carrying your own clubs. } \\
\text { Heavy carpentry. Pushing a lawn mower }\end{array}$ \\
\hline & 7 & $\begin{array}{l}\text { Perform heavy outdoors work e.g. digging } \\
\text { Walking uphill, tennis singles, carrying a 4-5 year old child }\end{array}$ \\
\hline & 8 & Move heavy furniture, jog slowly on the flat, carry a toddler up stairs \\
\hline & 9 & Cycling at a moderate pace, sawing wood \\
\hline & 10 & Brisk swimming, cycling uphill, walking briskly up hill, jog six miles per hour \\
\hline & 11 & Cross country skiing, carrying a heavy load up two flights of stairs, cycling briskly \\
\hline & 12 & Running briskly, continuously \\
\hline & 13 & $\begin{array}{l}\text { Any competitive activity, including those which involve intermittent sprinting. } \\
\text { Running or rowing competitively, cycling races }\end{array}$ \\
\hline
\end{tabular}

\begin{tabular}{|l|l|}
\hline $\begin{array}{l}\text { Please circle why you } \\
\text { would be likely to } \\
\text { stop }\end{array}$ & Short of breath \\
\cline { 2 - 2 } & Chest pain \\
\cline { 2 - 2 } & Palpitations \\
\cline { 2 - 2 } & Muscle pains or cramps \\
\cline { 2 - 2 } & Other \\
\hline
\end{tabular}

Figure 1 The UK-modified Veterans Specific Activity Questionnaire (VSAQ). The VSAQ as presented in the clinical service. Note 4 miles per hour is equivalent to $6.4 \mathrm{~km}$ per hour.

\section{RESULTS}

Development and optimisation of the UK-modified VSAQ scale The VSAQ lists multiple different activities for each of the 13 scale points, spanning day-to-day activities in addition to exercise. We anticipated this would be easy to complete by the patient, without clinician involvement, but noted that some activities referred to weights less familiar to UK patients. Prior to clinic introduction, we therefore made minor changes to the descriptions of activities to provide a UK-modified version (figure 1). A second modification to make it simpler for patients to fill in independently was to ask patients to circle every activity that made them want to stop, instead of just the first activity as in the original protocol.

The questionnaire was then tested in 44 individuals coming to the PAVM clinic for evaluation. Twenty-three were male and 22 were female, and ages ranged from 17 to 82 years (median 56.5 years). $\mathrm{SpO}_{2}$ erect ranged from $83 \%$ to $99 \%$ (38 patients were subsequently confirmed to have PAVMs). The symptoms that caused subjects to stop varied. Thirty-two subjects $(78 \%)$ described dyspnoea, 13 $(29.6 \%)$ muscle pain or cramps, $11(25 \%)$ palpitations and $5(11.4 \%)$ chest pain.'2nd'

While most subjects circled one activity, then all subsequent levels of activity sequentially, 13 of the $44(29.6 \%)$ described limitations of activities in two different groupings, some with gaps of more than four scale points which were difficult to explain just based on no pursuit of the activities suggested (figure 2). It was not initially clear which scale point should be used as the discriminator to calculate METs in such subjects. However, the pattern for chest pain and palpitations seemed to differ in subjects who had a gap between two groups of limited activities, resulting in different ' $1 \mathrm{st}$ ' and '2nd' VSAQ scores (online supplementary figure 2). Furthermore, subjects with differences of more than four scale points between their '1st' and '2nd' VSAQ scores (figure 2) were more likely to describe chest pain at the limit of their exercise capacity by '2nd' VSAQ 


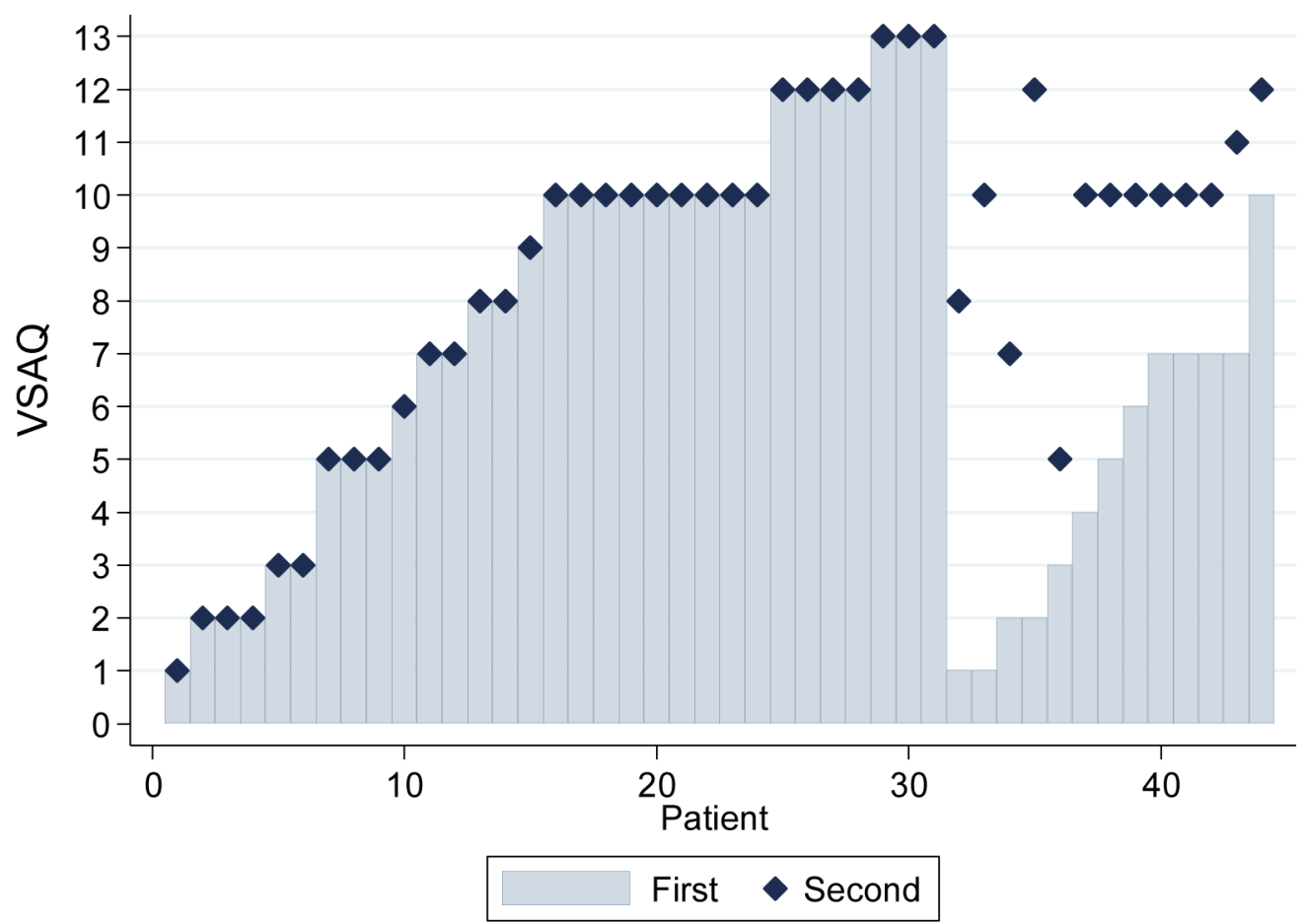

Figure 2 Veterans Specific Activity Questionnaire (VSAQ) scores as reported by the first 44 clinic patients. The least intense activity that patients reported made them need to stop is shown in grey bars as VSAQ 'first/1st', corresponding to the VSAQ captured in the original protocol. ${ }^{12}$ Some patients reported having to stop in two non-consecutive series of activities in terms of exercise intensity - the lowest VSAQ scale value of their second set of activities is denoted as VSAQ 'second/2nd' (navy diamond). Where there was no gap, VSAQ 'second' is denoted as identical to the VSAQ 'first'.

$(\mathrm{p}=0.0009)$. We concluded that the limitations identified by the '2nd' VSAQ score may differ from those identified by the '1st' t. Additionally, in normal quantile plots, the distribution of the '1st' VSAQ score was more normal than the '2nd' (online supplementary figure 3), an important factor if it were to be used as the outcome variable for regression and other statistical analyses in this rare disease population where study numbers will always be limited. We therefore used the '1st' VSAQ score, the lowest value at which exercise limitation was described, as validated in the general population. ${ }^{12}$

\section{VSAQ and MRC dyspnoea scores in the full cohort}

In total, between 16 March 2017 and 14 May 2018, 71 patients with PAVMs proven by CT scan completed the VSAQ prior to their clinic review. In this group, ages ranged from 20 to 85 (median 52) years, $\mathrm{SaO}_{2}$ from $80 \%$ to $99.5 \%$ (median 96\%), haemoglobin from 73 to 197 $\mathrm{g} / \mathrm{L}$ (median $136 \mathrm{~g} / \mathrm{L}$ ), and $\mathrm{CaO}_{2}$ from 8.6 to $21.9 \mathrm{~mL} /$ $\mathrm{dL}$. The particularly high prevalence of anaemia reflected the fact that many patients had frequent nosebleeds due to underlying hereditary haemorrhagic telangiectasia. As in the 2006-2010 PAVM cohort, ${ }^{6} \mathrm{CaO}_{2}$ was maintained by secondary erythrocytosis and polycythaemia, unless iron deficiency was present (figure 3).

The raw VSAQ data were used to derive approximate MRC Dyspnoea Scale and NYHA categories. The three scales are illustrated by gender in figure 4 . In keeping with previous data indicating well-preserved exercise tolerance in most patients with PAVMs, 49 of $71(69 \%)$ in the current cohort reported they did not need to stop until activities more energetic than walking briskly at $4 \mathrm{mph}(6.4 \mathrm{~km}$ per hour, VSAQ $>5$ ). As a result, only 27 patients $(38 \%)$ were in NYHA classes 2-4, and only 36 patients $(38 \%)$ in MRC classes 2-5.

In clinical practice it is widely assumed that patients with PAVM with lower $\mathrm{SaO}_{2}$ are more dyspnoeic and exercise-limited. By Kruskal-Wallis, there was no relationship between $\mathrm{SaO}_{2}$ and MRC Dyspnoea Scale $(\mathrm{p}=0.98)$, NYHA classification $(\mathrm{p}=0.12)$ or VSAQ $(\mathrm{p}=0.17)$, although trends did emerge applying linear and quantile regression (noting the skewed MRC Dyspnoea Scale and NYHA classifications). The crude $\mathrm{SaO}_{2}$ linear regression coefficient for the MRC Dyspnoea Scale was -0.95 (95\% CI -0.20 to $0.005)(\mathrm{p}=0.06)$, for NYHA -0.085 (95\% CI -0.15 to -0.18$)$ $(\mathrm{p}=0.013)$, and for the raw VSAQ score 0.22 (95\% CI -0.043 to 0.47$)(\mathrm{p}=0.10)$.

It was noted however that the raw VSAQ scale was capturing other differences, particularly that men were achieving higher levels of activity before stopping (figure 4). The difference was less pronounced using the MRC Dyspnoea Scale, and not captured by NYHA classification (table 1). $\mathrm{SaO}_{2}$ did not differ between men and women, but $\mathrm{CaO}_{2}$ was substantially lower in women, due to lower haemoglobin (table 1, figure 4). 


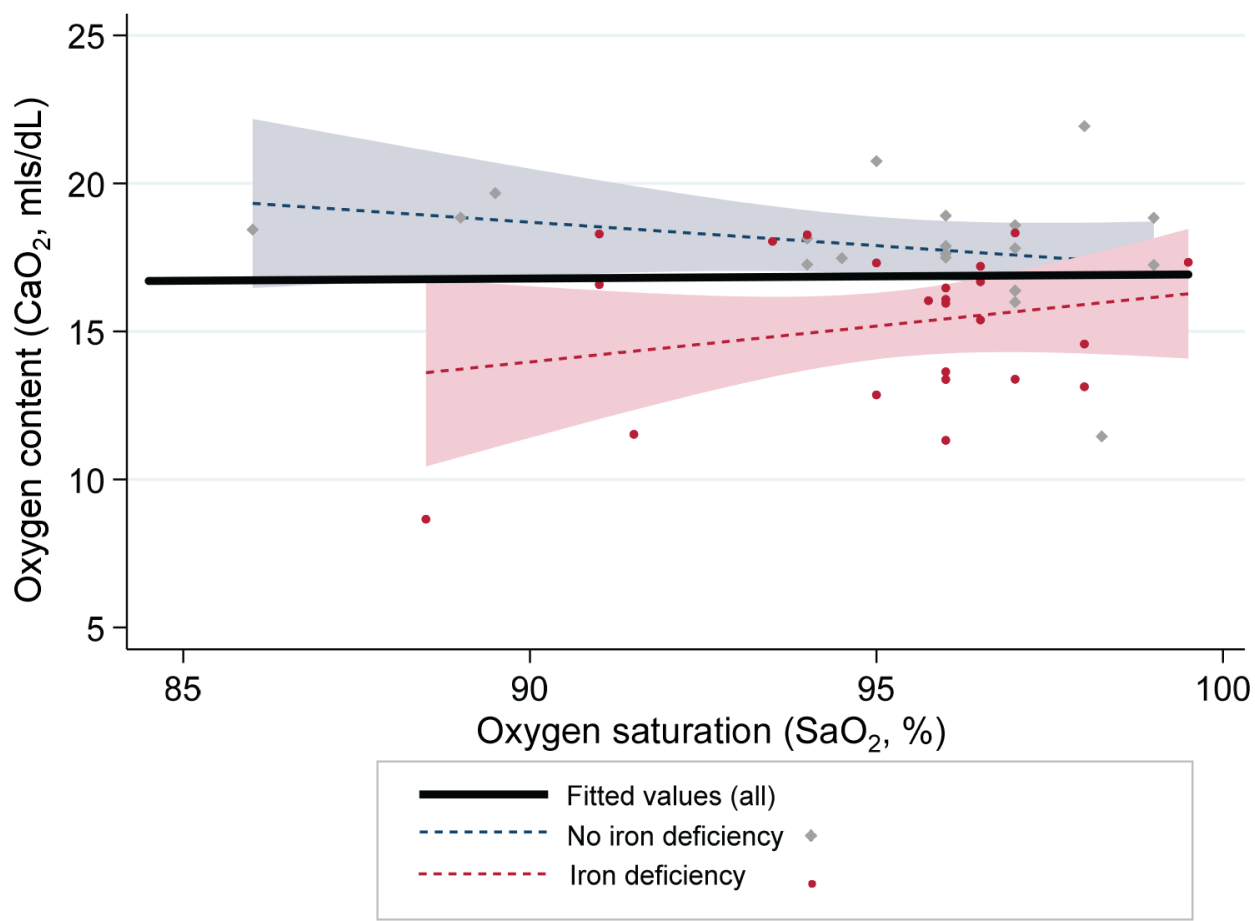

Figure 3 Relationship between arterial oxygen content $\left(\mathrm{CaO}_{2}\right)$ and oxygen saturation $\left(\mathrm{SaO}_{2}\right)$. CaO ${ }_{2}$ across all degrees of hypoxaemia was calculated by $\mathrm{SaO}_{2} \times$ haemoglobin $\times 1.34 / 100$, where $\mathrm{SaO}_{2}$ was expressed as $\%$, and $1.34 \mathrm{~mL}$ is the amount of oxygen carried per gram of haemoglobin. ${ }^{20}$ The bold black line represents the regression line for all patients, irrespective of iron status ( $p=0.87$ ). Grey circles/dotted line/shaded 95\% confidence intervals (Cls) represent patients without iron deficiency $(p=0.27)$. Red circles/dotted line/shaded $95 \%$ Cls represent patients with iron deficiency $(p=0.27)$.

\section{Associations with METs}

The VSAQ is not just a scale of activities, but also corresponds to validated calculated METs. In the 71 patients with PAVMs, METs ranged from 1.33 to $15.55 \mathrm{kcal} / \mathrm{kg} /$ minute (median 8.84, IQR 6.64-11.86), and were also significantly higher in men (3.97-15.55, median $8.84 \mathrm{kcal} / \mathrm{kg} / \mathrm{hour})$ than in women (1.33-14.4, median $8.25 \mathrm{kcal} / \mathrm{kg} / \mathrm{hour}$, $\mathrm{p}=0.0039$ ).

In univariate regression analyses, $\mathrm{SaO}_{2}$ was weakly associated with the age-adjusted METs ( $\mathrm{p}=0.044$; table 2$)$. Once adjusted for sex, lower $\mathrm{SaO}_{2}$ was more strongly associated with lower METs (adjusted $p$ value of 0.026), but this was not the most striking association.

Patients with hypoxaemia due to PAVMs compensate using secondary erythrocytosis. ${ }^{6} 18$

Haemoglobin ranged from 73 to 197 (median 136) $\mathrm{g} / \mathrm{L}$, and was significantly lower in women than in men (table 1). Haemoglobin was associated with the age-adjusted METs $(p=0.001)$, although the association was less pronounced when adjusted for sex (table 2). Overall, in crude and sex-adjusted regression, a haemoglobin increment of $10 \mathrm{~g} / \mathrm{L}(1 \mathrm{~g} / \mathrm{dL})$ was associated with approximately a twofold greater increase in METs than a $1 \%$ increment in $\mathrm{SaO}_{2}$ (table 2).

As we have shown previously, patients with hypoxaemia due to PAVMs generally maintain their $\mathrm{CaO}_{2},{ }^{6}{ }^{18}$ and this was observed in the current cohort (figure 3 ). $\mathrm{CaO}_{2}$ ranged from 8657 to 21930 (median 17 332) $\mathrm{mL}$ of oxygen/L, and was significantly higher in men than in women (table 1), reflecting the differing haemoglobin values and degree of iron deficiency (figure 3). In both crude and sex-adjusted regression, $\mathrm{CaO}_{2}$ was more strongly associated with METs than either $\mathrm{SaO}_{2}$ or haemoglobin in isolation (table 2).

\section{DISCUSSION}

We have shown that the VSAQ is an efficient and quantifiable measure of exercise capacity that discriminates between different levels of normal and athletic activity, in addition to mild, moderate and severe limitations. The initial 13-point scale can be readily employed in clinical service. Application captured a weak inverse association between $\mathrm{SaO}_{2}$ and exercise limitation as for the more usual, dyspnoea-weighted MRC and NYHA scales, but also revealed important associations with $\mathrm{CaO}_{2}$ reflecting haemoglobin concentrations and iron deficiency.

The primary reason for the introduction of the VSAQ was to facilitate discriminatory clinic assessments. Having nine separate scale points spanning the equivalent of NYHA class I, and MRC Dyspnoea Scales 1 and 2, allowed a more granular assessment of activity. Furthermore, the time completing is spent by patients, not clinicians who can instead focus on interpretations and clinical management. The patient-centric, non-directed approach is appreciated by patients who find it easy to complete, noting this relates to their normal activities and lifestyle. We calculated that our 

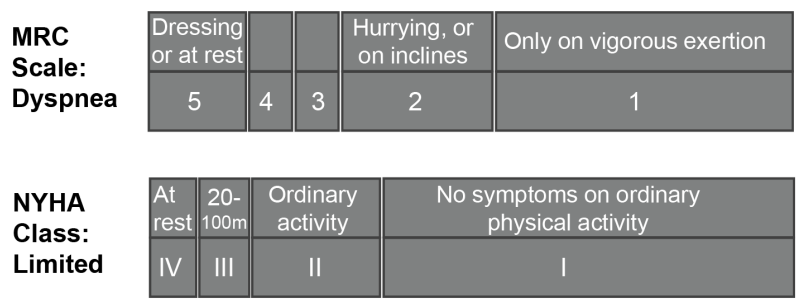

VSAQ
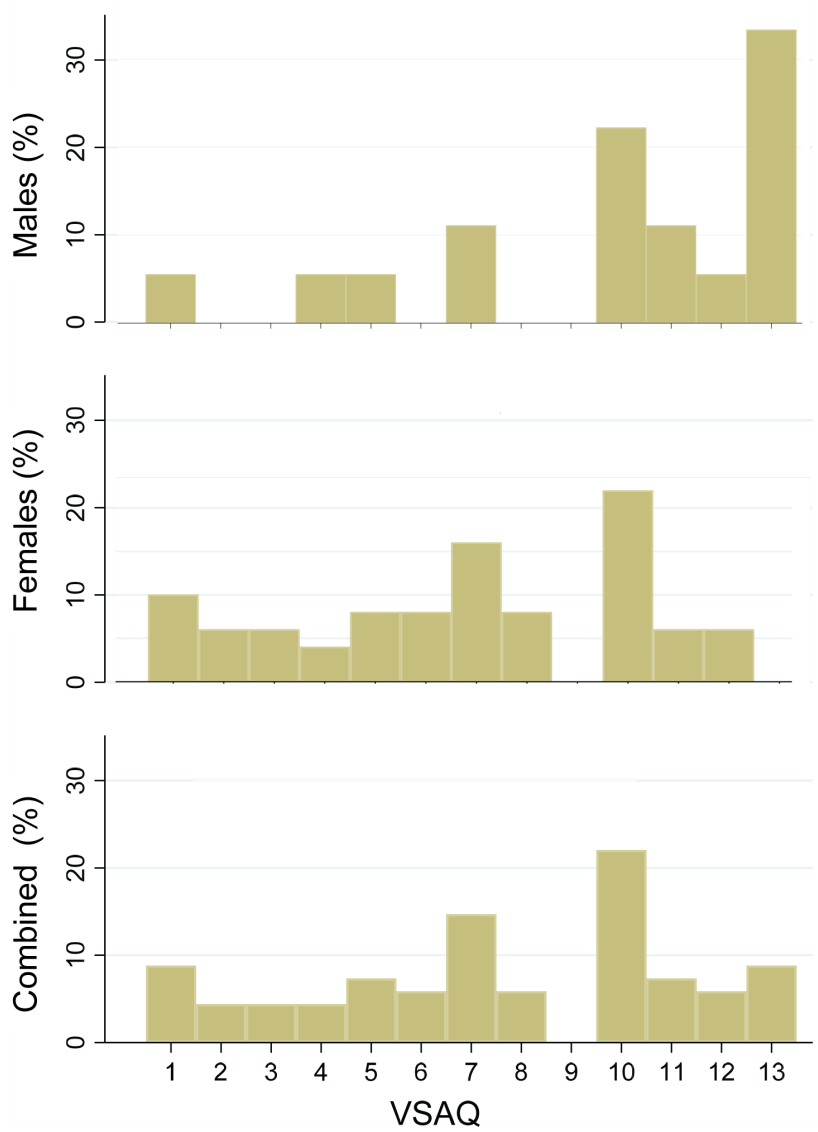

Figure 4 Activity limitation scores across the 71 patients with PAVMs in the study cohort. VSAQ scores (for men, women and combined) were denoted by the lowest number/first activity when a patient would typically have to stop (for details across the 1-13 VSAQ scale, see figure 1). These were approximated to the MRC Dyspnoea Scale and NYHA classification as indicated. MRC, Medical Research Council; NYHA, New York Heart Association; PAVM, pulmonary arteriovenous malformation; VASQ, Veterans Specific Activity Questionnaire.

previous assessments took a minimum of $27 \mathrm{~s}$ per patient, and usually considerably longer as patients selected their own activities, with some proceeding to expand in detail. In contrast, the patient-completed VSAQ enabled immediate clinician allocation of patients to athletic, normal or impaired exercise tolerance. Additionally, during the consultation, it allowed those whose capacity had changed to rapidly and objectively indicate where they would have been at a previous timepoint. In terms of clinical utility, it has proven immensely valuable.
The relatively limited association between $\mathrm{SaO}_{2}$ and METs mirrors the unchanged exercise capacity of patients with PAVM assessed by CPET before and after PAVM treatments that have improved their $\mathrm{SaO}_{2}{ }^{8}$ Instead, the indices of haemoglobin alone, or $\mathrm{CaO}_{2}$ (which is determined by haemoglobin and $\mathrm{SaO}_{2}{ }^{20}$ ), displayed marked differences between the genders and strong associations with METs. The observed relationships between METs and $\mathrm{SaO}_{2}$, haemoglobin, and $\mathrm{CaO}_{2}$ suggest the VSAQ will usefully discriminate incremental differences relating to very modest changes. We thus consider that the VSAQ is ideally suited to long-term follow-up of patients with PAVMs before and after treatment of anaemia/iron deficiency, in addition to pre-PAVM/post-PAVM treatments or other incidental pathologies/lifestyle changes.

The pattern displayed by patients reporting two different groups of exercise limitations (and hence '1st' and '2nd' VSAQ scores; figure 2) deserves comment. The finding could reflect factors such as differing patient effort, prior muscle training or familiarity, although there are physiological reasons why the study cohort may differ from the general population. An increased resting heart rate, exuberant postural tachycardia and increased ventilatory rate are three of the compensatory mechanisms for PAVMs, ${ }^{8}{ }^{10}$ although despite these physiological compensations, as exercise becomes more demanding, patients with PAVMs have been shown to have perceived dyspnoea no greater than controls. ${ }^{8}$ This could explain why limitation by activities in the middle range of the VSAQ was not seen as often-essentially that low level activities may be more challenging for patients who rapidly increase their heart rate, including on standing. ${ }^{7}$ When metabolic requirements

\begin{tabular}{|c|c|c|c|}
\hline & Male & Female & $P$ value \\
\hline Age & $50(20-81)$ & $53(20-85)$ & 0.37 \\
\hline $\begin{array}{l}\text { MRC Dyspnoea } \\
\text { Scale }\end{array}$ & $1(1-5)$ & $2(1-5)$ & 0.032 \\
\hline NYHA class & $1(1-4)$ & $1(1-4)$ & 0.13 \\
\hline VSAQ score & $10.5(1-13)$ & $7(1-12)$ & 0.0018 \\
\hline $\mathrm{SaO}_{2}(\%)$ & 96 (89-98) & $96(80-96)$ & 0.67 \\
\hline $\mathrm{CaO}_{2}(\mathrm{~mL} / \mathrm{L})$ & 189 (160-219) & $168(87-194)$ & 0.0003 \\
\hline Haemoglobin $(\mathrm{g} / \mathrm{L})$ & $152(123-197)$ & $132(73-169)$ & 0.0004 \\
\hline Serum iron $(\mu \mathrm{mol} / \mathrm{L})$ & $14(7-35)$ & $11(1-48)$ & 0.020 \\
\hline $\begin{array}{l}\text { Transferrin } \\
\text { saturation index (\%) }\end{array}$ & $22.5(6-54)$ & $15(1-66)$ & 0.016 \\
\hline Ferritin $(\mu \mathrm{g} / \mathrm{L})$ & $54(11-306)$ & $26(3-160)$ & 0.024 \\
\hline
\end{tabular}

Selected demographics of the 71 patients with PAVMs. Data indicate median (minimum to maximum). $P$ values were calculated by Mann-Whitney. Note that in this cohort, the MRC Dyspnoea Scale and NYHA class equivalents were assigned from the VSAQ score (see figure 3).

$\mathrm{CaO}_{2}$, arterial oxygen content; MRC, Medical Research Council; NYHA, New York Heart Association; PAVM, pulmonary arteriovenous malformation; $\mathrm{SaO}_{2}$, oxygen saturation; VSAQ, Veterans Specific Activity Questionnaire. 
Table 2 Linear regression analyses using METs as the outcome variable

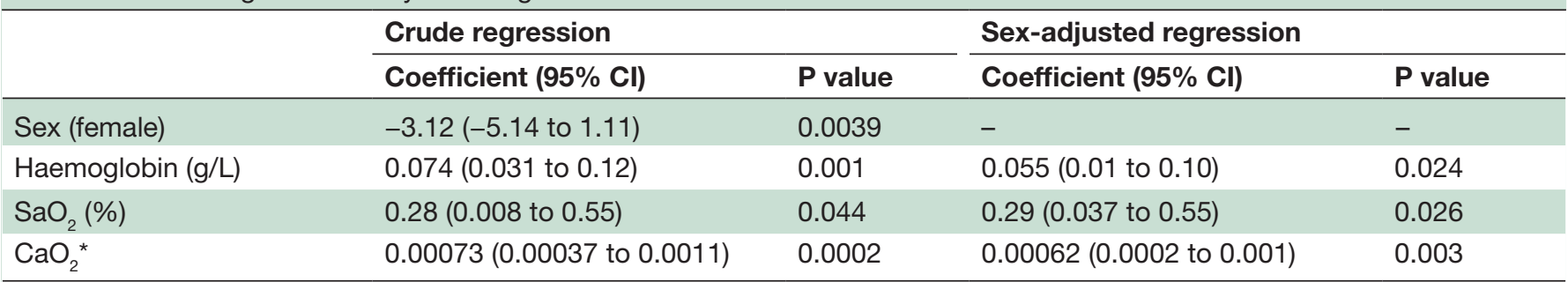

Normal quantile plots (online supplementary figure 3) supported the use of METs ('1st' METs) as the dependent variable.

${ }^{*} \mathrm{CaO}_{2}$ unit $\mathrm{mL}$ of oxygen/L.

$\mathrm{CaO}_{2}$, arterial oxygen content; METs, metabolic equivalents; $\mathrm{SaO}_{2}$, oxygen saturation.

increase, increased stroke volume enables the higher required cardiac outputs until the patients reach their exercise limit, ${ }^{8}$ and this is where the second VSAQ score would be indicated.

The study has several limitations, particularly the study number, the absence of invasive measurements and the reliance on patient-reported activity. Within these limitations, it still provided data that we believe will encourage wider application in respiratory medicine.

In summary, the VSAQ is an efficient and quantifiable measure of exercise capacity using patient-reported outcome measures that can be readily employed in clinical service. In the PAVM population, exercise capacity reflects haemoglobin and calculated $\mathrm{CaO}_{2}$ more than $\mathrm{SaO}_{2}$, even where $\mathrm{SaO}_{2}$ measurements are low.

Contributors FG selected the VSAQ for PAVM clinic assessments, assisted in modification and optimisation, generated the 2017-2018 database, performed literature studies, generated the PAVM clinic database and drafted manuscript sections. JM generated the VSAQ, advised on physiological concepts and contributed to data interpretation. CS devised the study, supervised FG, reviewed all patients, performed literature searches, analysed and interpreted the data, performed all presented data analyses, generated the tables and figures, and wrote the final manuscript. All authors contributed to and approved the final version of this manuscript.

Funding The authors have not declared a specific grant for this research from any funding agency in the public, commercial or not-for-profit sectors.

Competing interests None declared.

Patient consent for publication Not required.

Ethics approval The study was ethically approved by the Hammersmith, Queen Charlotte's, Chelsea and Acton Hospitals Research Ethics Committee (LREC 2000/5764).

Provenance and peer review Not commissioned; externally peer reviewed.

Data sharing statement The authors fully agree with the principles of data sharing and will share fully anonymised data on reasonable request.

Open access This is an open access article distributed in accordance with the Creative Commons Attribution Non Commercial (CC BY-NC 4.0) license, which permits others to distribute, remix, adapt, build upon this work non-commercially, and license their derivative works on different terms, provided the original work is properly cited, appropriate credit is given, any changes made indicated, and the use is non-commercial. See: http://creativecommons.org/licenses/by-nc/4.0/.

\section{REFERENCES}

1. Shovlin CL. Pulmonary arteriovenous malformations. Am J Respir Crit Care Med 2014;190:1217-28.

2. Chilvers ER, Peters AM, George P, et al. Quantification of right to left shunt through pulmonary arteriovenous malformations using $99 \mathrm{Tcm}$ albumin microspheres. Clin Radiol 1988;39:611-4.

3. Ueki J, Hughes JM, Peters AM, et al. Oxygen and 99mTc-MAA shunt estimations in patients with pulmonary arteriovenous malformations: effects of changes in posture and lung volume. Thorax 1994;49:327-31.

4. Thompson RD, Jackson J, Peters AM, et al. Sensitivity and specificity of radioisotope right-left shunt measurements and pulse oximetry for the early detection of pulmonary arteriovenous malformations. Chest 1999;115:109-13.

5. Duke JW, Davis JT, Ryan BJ, et al. Decreased arterial $\mathrm{PO}_{2}$, not $\mathrm{O}_{2}$ content, increases blood flow through intrapulmonary arteriovenous anastomoses at rest. J Physiol 2016;594:4981-96.

6. Santhirapala V, Williams LC, Tighe HC, et al. Arterial oxygen content is precisely maintained by graded erythrocytotic responses in settings of high/normal serum iron levels, and predicts exercise capacity: an observational study of hypoxaemic patients with pulmonary arteriovenous malformations. PLoS One 2014;9:e90777.

7. Santhirapala V, Chamali B, McKernan H, et al. Orthodeoxia and postural orthostatic tachycardia in patients with pulmonary arteriovenous malformations: a prospective 8-year series. Thorax 2014:69:1046-7.

8. Howard L, Santhirapala V, Murphy K, et al. Cardiopulmonary exercise testing demonstrates maintenance of exercise capacity in patients with hypoxemia and pulmonary arteriovenous malformations. Chest 2014;146:709-18.

9. Shovlin CL, Condliffe R, Donaldson JW, et al. British Thoracic Society Clinical Statement on Pulmonary Arteriovenous Malformations. Thorax 2017;72:1154-63.

10. Whyte MK, Hughes JM, Jackson JE, et al. Cardiopulmonary response to exercise in patients with intrapulmonary vascular shunts. J Appl Physiol 1993;75:321-8.

11. Fletcher CM. Standardised questionnaire on respiratory symptoms: a statement prepared and approved by the MRC committee on the aetiology of chronic bronchitis (MRC breathlessness score). BMJ 1960;2:1665.

12. Criteria Committee New York Heart Association Inc. Diseases of the heart and blood vessels. Nomenclature and criteria for diagnosis. 6th edn. Boston: Little Brown and Co, 1964: 114

13. Myers J, Do D, Herbert W, et al. A nomogram to predict exercise capacity from a specific activity questionnaire and clinical data. Am J Cardiol 1994;73:591-6.

14. Kojima S, Wang DH, Tokumori K, et al. Practicality of veterans specific activity questionnaire in evaluation of exercise capacity of community-dwelling Japanese elderly. Environ Health Prev Med 2006-313-20.

15. Myers J, Bader D, Madhavan R, et al. Validation of a specific activity questionnaire to estimate exercise tolerance in patients referred for exercise testing. Am Heart J 2001;142:1041-6.

16. Kojima S, Wang DH, Tokumori K, et al. Practicality of veterans specific activity questionnaire in evaluation of exercise capacity of community-dwelling Japanese elderly. Environ Health Prev Med 2006;11:313-20.

17. McAuley P, Myers J, Abella J, et al. Evaluation of a specific activity questionnaire to predict mortality in men referred for exercise testing. Am Heart J 2006;151:e1-7.

18. Rizvi A, Babawale L, Tighe HC. Hemoglobin is a vital determinant of arterial oxygen content in hypoxemic patients with pulmonary arteriovenous malformations: a 17 year prospective follow up series, 2016.

19. Shovlin CL, Chamali B, Santhirapala V, et al. Ischaemic strokes in patients with pulmonary arteriovenous malformations and hereditary hemorrhagic telangiectasia: associations with iron deficiency and platelets. PLoS One 2014;9:e88812.

20. Pittman RN. Regulation of tissue oxygenation. San Rafael CA, $2011: 1$. 